\title{
Model of Radio Managing System for Electro Vehicles' Accumulators Wireless Feeding
}

\author{
Hrayr Abrahamyan ${ }^{1,2}$, Arevik Sargsyan ${ }^{1,2}$, David Davtyan ${ }^{1}$, Harutyun Minasyan ${ }^{1}$ \\ 1 - State Engineering University of Armenia, Teryan str. 105, 0009 Yerevan, Armenia \\ 2 - National Institute of Metrology, Komitas Ave. 43/2, Yerevan, Armenia \\ h.abrahamyan@seua.am, (+37498)109810
}

\begin{abstract}
This article refers to studying of the system for wireless feeding of electro vehicles' accumulators, and the description of it's applicable efficiency. Preliminary design of the radio managing system is done. The electro vehicle feeding system is calculated for the freeway. By using LabVIEW program package model of radio managing system was designed.
\end{abstract}

Keywords: electro vehicle, wireless feeding, resonant induction, rectenna, radio managing system, LabVIEW program package.

\section{INTRODUCTION}

According to projections oil, natural gas and other mineral fuel reserves will run out within the next 50 years. Developing tendencies of vehicles are adequately connected with alternative power. Electro vehicles, as means of alternative fuel fed transportation, are widely developing nowadays [1]. Certainly, electro vehicles, are considered to be transportation of future, but it is important to mention, that for nowadays' development there are many obstacles. Supply of electrical batteries can be implemented in special-home charging stations, but they are time consuming.

There are many Companies, who's technological approach and principles are based on Inductive Power Transfer (IPT) idea. IPT wireless charging is widely used by magnetic resonance to transfer power from a transmitting pad on the ground to a receiving pad on electric vehicle. That's why an IPT wireless charging system comprises two separate elements: a primaryside power supply with track; and a secondary-side pick-up pad with controller. In order to charge the electric vehicle, it is simply required to park the car over a pad $[2,3]$.

Recently, extensive work has been done for wireless and dynamic power of accumulators of electro vehicles. In some works electric vehicles charge wirelessly via underground electricity induction for dynamic charging of accumulators has been used. It gives opportunity for the electro vehicle to have powered accumulators along the whole road, but that technologies come to be difficult and expensive. The problems of charging the accumulators of electro vehicles, will find their solution by using wireless power transmission technology [4-7].

Wireless power transmission technology via microwave was advanced from 1960's [8]. The rectenna, rectifying antenna, is one of the primary components in the application of wireless power transmission system. The rectenna has receives much attention in the development process of transmission for receiving and converting the microwave power to direct current power. The application of this technology can be used in radio-frequency identification and electric vehicles [6,9].

\section{MATERIALS AND METHODS}

In our previous work we have suggested sketch project of wireless system electro vehicle accumulator power by using the radio management system. It enabled the accumulator charging of electro vehicle during it's movement. The system is based on wireless transmission of electrical energy. Appropriate calculations, based on characteristics of technical description of electro vehicles were done in the work. Cases of both sided traffic as well as opportunity to provide electrical supply of several electro vehicles were examined [4].

The transmitter parts of the components of radio managing system are: power source (PS), modulator (M), transmitter (T), Radio managing system (RMA) which, after receiving the relevant information from the electro mobile, determine the coordinates and movement speed, and with the help of automation device (AD) realizes beam-controlling (BC). Radio RMA verifies the customer with all the necessary information and coordinates the entire feeding process. The receiver system's component parts are: rectena $(\mathrm{R})$, receiver (Rec), demodulator (DM), car accumulator (Ac). The accumulator provides the necessary information about the need of accumulator charge or the end of feeding process, then the information is processed by the information processing device (IPD) and is reported to RMS. The latter checks the necessary information connected with the customer and conducts the feeding process. 


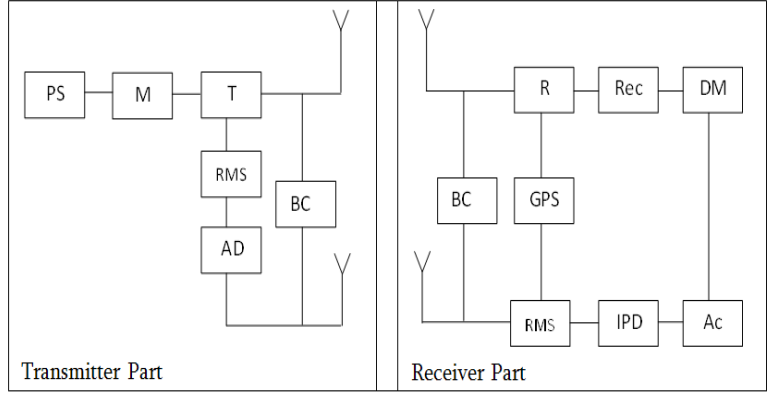

Fig.1. The sketch scheme of radio managing system

According to accumulator charging data, in order to provide the average speed of $80 \mathrm{~km} / \mathrm{h}$ it will take 110 $\mathrm{W} * \mathrm{~h} / \mathrm{km} * 80 \mathrm{~km} / \mathrm{h}=8.8 \mathrm{~kW}$ capacity [1] .Fully charged electro vehicle, which is $4.4 \mathrm{kWt} / \mathrm{h}$ passes $40 \mathrm{~km}$. It means, that within an hour it needs two refills, but if charging is constant. It means, that no less than $2.5 \mathrm{~W}$ of energy supply is needed to provide. We accept reported antenna gain no less than $30 \mathrm{~dB}$, the signal wave length being reported $\lambda=3 \mathrm{~m}$ Based on strength construction, plant height was calculated up to $h_{1}=30 \mathrm{~m}$, height of electro vehicle $h_{2}=2 \mathrm{~m}$.

Based on these data, by using well-known radiolocation formula, the maximum radiation power was calculated, and was built a graph describing the distance dependence from the transmission power [4].

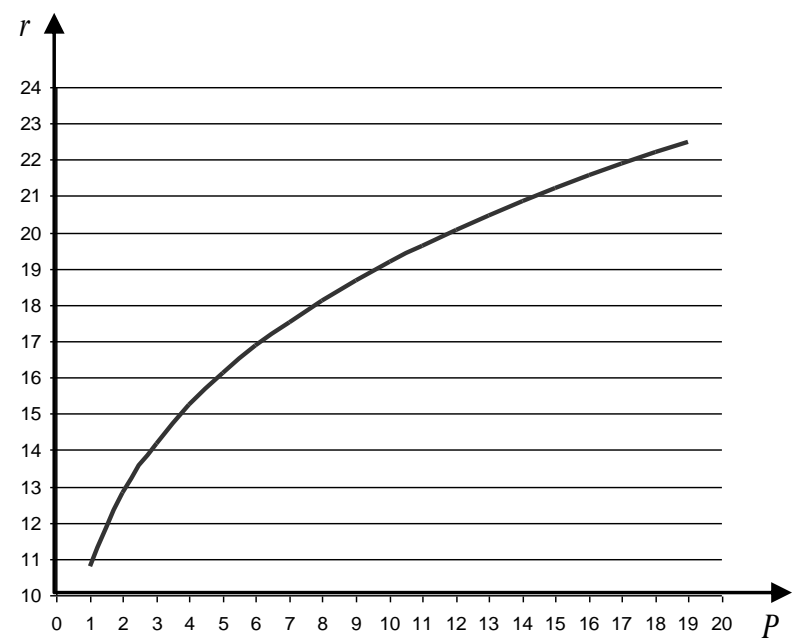

Fig. 2. Dependence of radiation distance from power transmission

From the graphic (figure.2) it is easy to see that in case of $\mathrm{P}=5 \mathrm{~W}$ value for $\mathrm{r}$ we shall get $r=16 \mathrm{~km}$. As service road segment was taken Ararat region M-2 motorway in Armenia, and specifically AraratArtashat $20 \mathrm{~km}$ long section (figure 3).

In order to get power system with great efficiency the spherical mirror antenna and Phase Array Antenna complex were chosen. [10,11]. As the spherical mirror antenna complex can provide a maximum $120^{\circ}$ angle visibility, the distance from the road outside the station is approximately $6 \mathrm{~km}$. So, in case of having one station, it is possible to supply $20 \mathrm{~km}$ of the road segment.

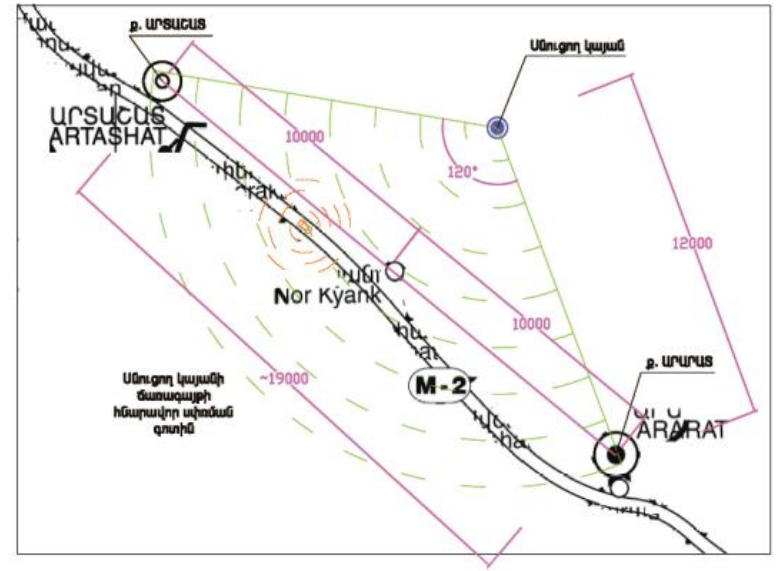

Fig.3. The coverege of feeding station

\section{RESULTS AND DISCUSSION}

By using spherical mirror antenna and Phase Array Antenna it becomes possible to provide independent and separately managed beams in space. By using LabVIEW programming package was developed the digital beam-forming scheme of antenna array, which allows to managing antenna radiation pattern (RP). This model is based on antenna array mathematical model. The signal, which is radiating by the Phase Array Antenna each element, can be represented by the following formula.

$\dot{X}_{n}=\frac{I_{n}}{I_{0}} e^{j k n d \cdot \sin (\theta)}$,

Here $\mathrm{Xn}$ is complex description, which is obtained from array of $n$-th element under $\theta$, angle: $I_{n} / I_{0}$ the power distribution between the elements, K-number of waves, D-distance between feeding elements.

Output signal is formed by all incoming signals and weight coefficient of feeding elements multiplicative complexive amount.

$$
\dot{\mathrm{U}}_{\mathrm{n}}(\theta)=\sum_{\mathrm{n}=0}^{\mathrm{N}-1} \dot{\mathrm{W}}_{\mathrm{n}}^{\mathrm{H}} \cdot \dot{\mathrm{X}}_{\mathrm{n}},
$$

Where $\dot{\mathrm{W}}_{\mathrm{n}}^{\mathrm{H}}$ the conjugate matrix weight coefficient for the n-th path, $\mathrm{N}$ - is number of feeding elements in antenna array. Antenna RP can be changed from $-180^{\circ}$ to $+180^{\circ}$.

The front panel appearance designed by LabVIEW program package is shown in figure 4, and the functional part of the block diagram is shown in figure 5 . 


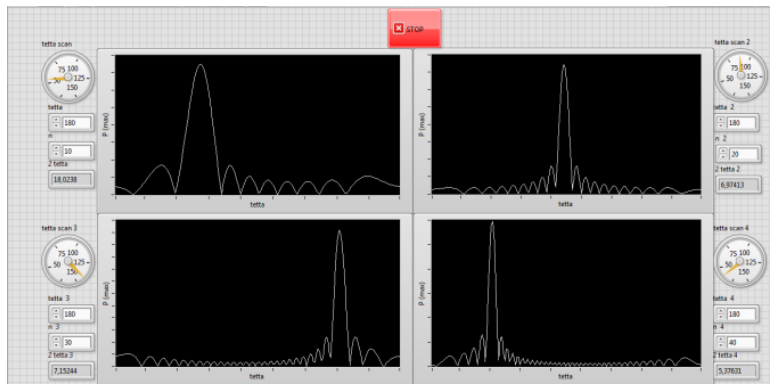

Fig.4. Front panel of mathematical modeling of radiation pattern

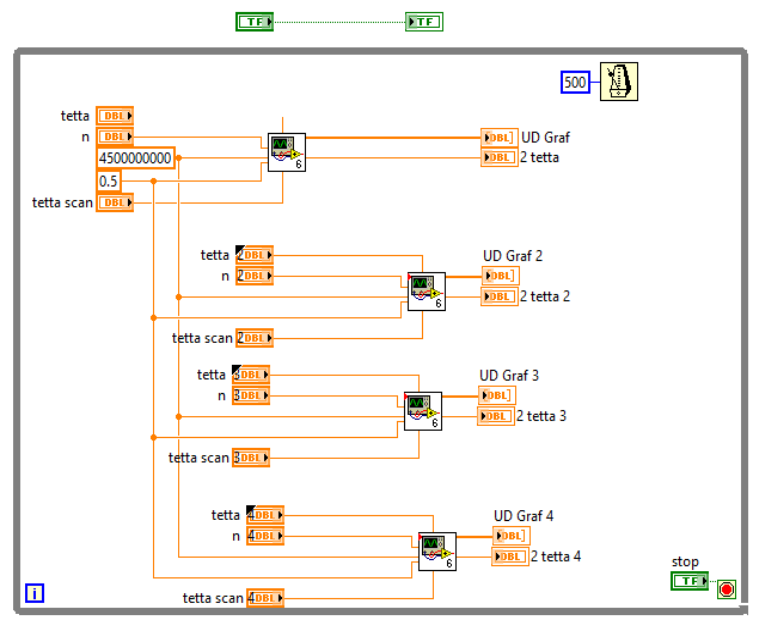

Fig.5 Block diagram of mathematical modeling of radiation pattern

This model allows to configure one and multi beam system antenna array. The Front panel presents antenna RP based on Cartesian coordinate system. This work simulates antenna array with 4 beams. Each beam can be scanned (Beam scanning) through the program. This model makes possible to control all 4 radiation patterns simultaneously.

The model of wireless accumulator charging system of electro vehicles was developed using LabVIEW program package. Receiver and transmitter antennas' RP automatic alignment is working continuously. With the help of narrow beam it enables to charge not only real but also mobile units, providing continuous charging, with the help of GPS system. The calculation of antennas RP alignment are being determined by coordinates of GPS system: At first, the distance between transmitter and receiver stations is being calculated by Haversine formula. Then the angular coordinates between stages are calculated.

$\mathrm{d}=2 \mathrm{r} \arcsin \left(\sin ^{2}\left(\frac{\phi_{2}-\phi_{1}}{2}\right)+\cos \phi_{1} \cos \phi_{2} \sin ^{2}\left(\frac{\lambda_{2}-\lambda_{1}}{2}\right)\right)$

$\mathrm{d}$ - distance between two points.

$r$ - the average radius of the Earth

$\phi_{1} \lambda_{1}$ and $\phi_{2} \lambda_{2}$ the stations coordinates.

The front panel receiver part and antennas RP alignment with the help of GPS system designed by LabVIEW program package is shown in figure 6 , and the functional part of the block diagram is shown in figure 7.

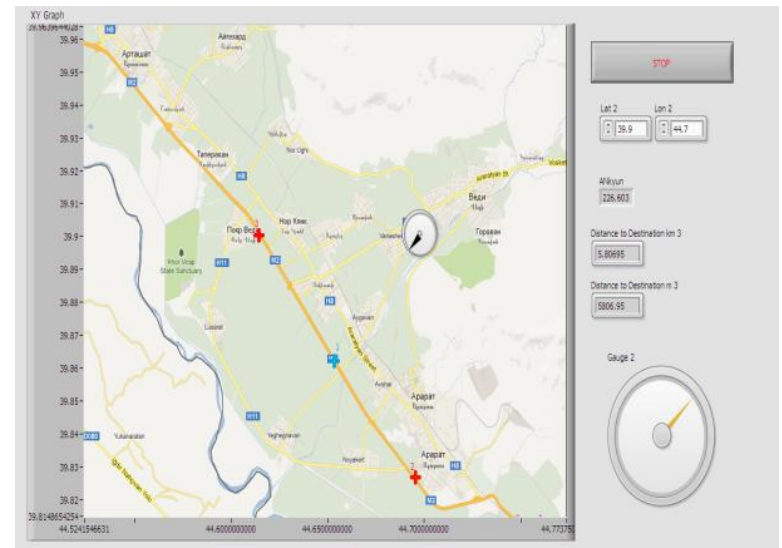

Fig.6. Front panel of receiver part and antennas RP alignment
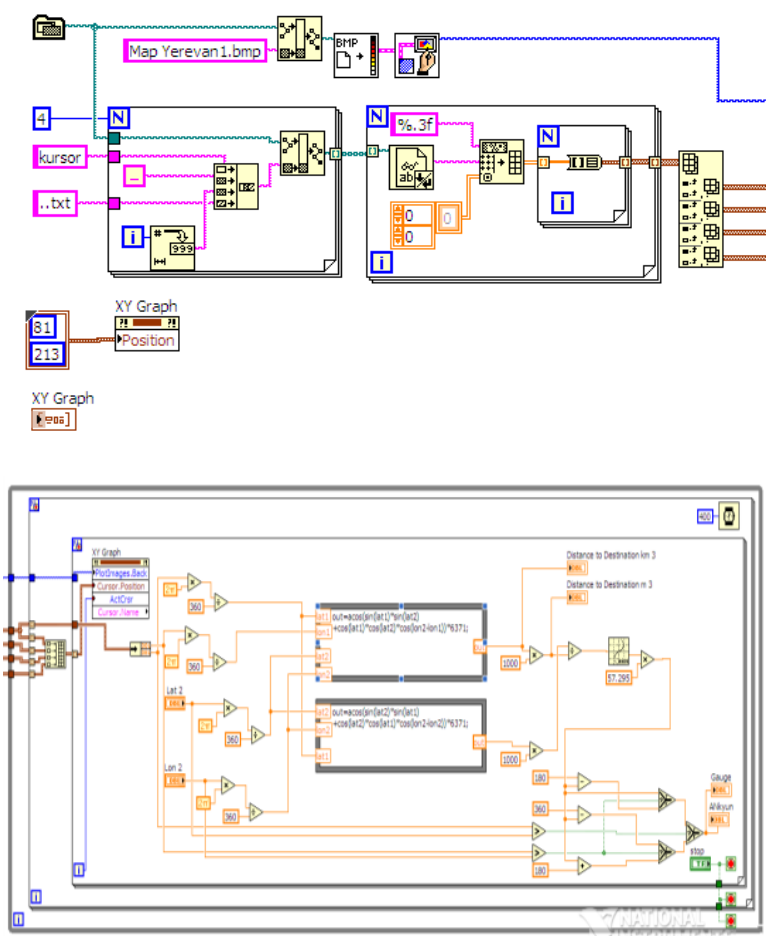

Fig.7. Block diagram of receiver part and antennas radiation pattern alignment

\section{CONCLUSION}

The radio managing system of feeding process of accumulators of electro mobiles provides both moving and stationary objects accumulator feeding efficiency. The model of wireless feeding process by using LabVIEW program package will give opportunity to provide high efficiency and dynamic regime of feeding process. The model will also give the opportunity to control one and multi beam antenna array, enabling the tracing ability. Also, the model which has an opportunity of alignment antennas RP will allow minimization of feeding losses. 
Abrahamyan H., Sargsyan A., Davtyan D., Minasyan H. MODEL OF RADIO MANAGING SYSTEM FOR ELECTRO VEHICLES'ACCUMULATORS WIRELESS FEEDING

\section{REFERENCES}

[1] www.commutercars.com

[2] http://www.qualcomm.com/solutions/wirelesscharging/qualcomm-halo\#n_home-intro

[3] http://www.treehugger.com/cars/e-cars-and-buses-chargemagically-with-underground-induction.html

[4] Sargsyan A., Abrahamyan H., Khocharyan H. Study of the Radio Managing System for Wireless Feeding of Electro Vehicle's Accumulators. Lraber-76, SEUA (Polytechnic), Collection of scientific and methodical papers. - Part1 №2. Yerevan 2008. -Pp. 343-345.

[5] Landis G. A, "Charging of Devices by Microwave Power Beaming," U.S. Patent 6,967,46, November 22 2005)

[6] Chang-Jun Ahn, Takeshi Kamio, Hisato Fujisaka, Kazuhisa Haeiwa. Prototype of $5.8 \mathrm{GHz}$ Wireless Power Transmission System for Electric Vehicle System. 2nd International Conference on Environmental Science and Technology. IPCBEE vol.6 (2011) C (2011) IACSIT Press, Singapore. pp. 126-131. 2011.
[7] Vijay Kumar A., Niklesh P., Naveen T., Wireless Power Transmission. International Journal of Engineering Research and Applications (IJERA), Vol. 1, Issue 4, pp. 1306-1310.

[8] W.C. Brown, "The history of power transmission by radio waves," IEEE Transactions on Microwave Theory and Techniques, vol. 32, no. 9, pp.1230-1242, Sept. 1984.

[9] Christi Walsh, Sebastien Rondineau, Milos Jankovic, George Zhao, Zoya Popovic, "A Conformal $10 \mathrm{GHz}$ Rectenna for Wireless Powering of Piezoelectric Sensor Electronics," to be presented at the 2005 IEEE International Microwave Symposium, Long Beach, June2005.

[10] Sargsyan A., Architectural Design of the Multiple Feed Spherical Reflector Terminal, 29th ESA Antenna Workshop on Multiple Beams and Reconfigurable Antennas, ESTEC, 1820 April, 2007.

[11] Abrahamyan H. Synthesis of Reconfigurable Slotted Waveguide Array Antenna. Environment. Technology. Resources // Proceedings of the 8th International Scientific and Practical Conference, Latvia /Rezekne/. Volume II.,Rezekne 2011, June 20-22, 2011.- P. 211-216. 